\title{
DISCURSO SOBRE LÍNGUA: O DESENVOLVIMENTO COMO EIXO DO DEBATE SOBRE DIVERSIDADE LINGUÍSTICA. UM OLHAR NA DECLARAÇÃO UNIVERSAL DOS DIREITOS LINGUÍSTICOS ${ }^{1}$
}

\author{
Damaris Heidi Cristobal Suvderlan² \\ Eliana Rosa Sturza ${ }^{3}$
}

\section{Resumo}

O presente artigo tem como objetivo compreender como o desenvolvimento linguístico é designado, dito e (re) significado na "Declaração universal dos direitos linguísticos", texto jurídico que oficializa um debate e um longo processo de reflexões acerca da diversidade linguística no marco das políticas de línguas. Para isso, realizou-se um percurso no contexto da criação da Declaração e as finalidades principais que a regem. O trabalho considera a Declaração como um acontecimento enunciativo, enquadrado na Semântica do Acontecimento e na proposta da História das Ideias Linguísticas.

Palavras-chave: desenvolvimento linguístico, políticas de línguas, História das ideias linguísticas, semântica do acontecimento.

\section{Resumen}

El presente artículo tiene como objetivo comprender cómo el desarrollo lingüístico es designado, dicho y resignificado en la "Declaración universal de los derechos lingüísticos", texto jurídico que oficializa un debate y un largo proceso de reflexiones acerca de la diversidad lingüística en el marco de las políticas de lenguas. Para esto, se realizó un recorrido al contexto de la creación de la Declaración y las principales finalidades que la rigen. El trabajo considera a la Declaración como un acontecimiento enunciativo, encuadrado en la Semántica del Acontecimiento y la propuesta de la Historia de las Ideas Lingüísticas.

Palabras clave: desarrollo lingüístico, políticas de lenguas, Historia de las ideas lingüísticas, semántica del acontecimiento

\section{Considerações iniciais}

Falar de diversidade linguística supõe ingressar em um âmbito no qual confluem o jurídico, o social, o político e também sua relação com as "ciências da linguagem" (Auroux, 1992). De acordo com o afirmado por Guimarães (2005), a língua é heterogênea, polissêmica e, por isso, dividida, desigual. Nesse sentido, estabelece-se uma relação estreita entre a língua e seus falantes. "E esta divisão diz respeito exatamente à relação dos falantes com a língua, de tal modo que os falantes se identificam exatamente por essa divisão" (GUIMARÃES, 2005, p. 21).

Desde esta perspectiva, reconhece-se que a língua não é igual para todos seus falantes. Porém, constitui para todos eles, segundo Guimarães (2005), um modo de

1 Artigo desenvolvido na disciplina Produção do Conhecimento Linguístico do Programa de Pós-Graduação em Letras, da Universidade Federal de Santa Maria/UFSM, ministrada pela professora Dra. Eliana Sturza. 2 Aluna-mestranda do Programa de Pós-graduação em Letras da UFSM. E-mail: d.suvderlan@gmail.com

3 Professora Doutora do Programa de Pós-Graduação em Letras da Universidade Federal de

Santa Maria (UFSM), orientadora e coautora deste trabalho. E-mail: listurza@gmail.com 
significar sua história, porque a língua é história, é histórica. Nesse sentido, observa-se um reconhecimento, desde o âmbito teórico, da diversidade linguística como uma compressão da pluralidade humana, cultural, identitária. Contrariamente, quando este contato se traslada às relações sociais, segundo Orlandi (2002), o debate sobre a língua é afetado pela relação do sujeito com o Estado. Em outras palavras, ingressa-se no campo do político.

Nesse sentido, surge, dentro do afirmado por Orlandi (2002), as Políticas de Línguas que assumem que o político se inscreve na língua no ato de falar. Devido a que na linguagem mesma se encontram implícitas relações sociais, históricas e de poder. Este vínculo é desenvolvido por Guimarães (2005, p.16), entendido como "fundamento das relações sociais". De acordo com ele, a divisão estabelecida pela norma e a afirmação de pertença dos falantes a sua língua se encontram em um estado de contradição, que constitui uma característica do político. A linguagem, segundo Guimarães (2005), configura o espaço em que se expressam estas contradições.

Esta proposta se associa ao afirmado por Mariani (2005), quem propõe que a língua é um espaço de disputa de poder entre instâncias sociais que litigam por controlar as práticas simbólicas e a produção de sentidos dentro de uma sociedade. Em consequência, reafirma-se o proposto por Orlandi (2002), ao afirmar que a língua, a Ciência e a Política mantêm entre si relações profundas que definem a constituição dos sujeitos e dão forma à sociedade. Nessas relações de enunciação, precisamente, se situam os estudos de políticas linguísticas.

A noção de política linguística adquire outro sentido. Ao se definir a língua se fala, com que estatuto, onde, quando, e os modos de acesso a ela -pelo ensino, pela produção de instrumentos linguísticos, pelo acesso a publicações, pela participação em rituais da linguagem, pela legitimação de acordos, pela construção de instituições linguísticas- estáse praticando as várias formas das políticas de língua, ao mesmo tempo em que, para identificá-la, está-se produzindo seu conhecimento, sua análise, e dando a ela configuração singular. (ORLANDI, 2002, p. 125126).

Nesta lógica, os estudos em políticas linguísticas, segundo Orlandi (2002), não compreendem unicamente as políticas públicas, mas também os processos mais complexos presentes no uso de uma língua e no debate sobre ela. Precisamente, os dizeres deste debate, dentro do afirmado pela autora, são designados como de dizernas e dizer sobre as línguas. Como objetivo deste trabalho, serão estudados os sentidos inscritos nos usos e nas referências que, no discurso jurídico, se faz das línguas e sobre as línguas.

De acordo com Guimarães (2005), a proposta teórica de políticas de línguas se associa com a Teoria da Enunciação e com a Semântica do Acontecimento, enquanto esta toma a língua em seu funcionamento, como espaço de poder, disputa política. A respeito, Auroux (2006 apud NUNES 2008a) esclarece que os conhecimentos não são acontecimentos e, por isso, não têm data, são eventuais aparecimentos. Para que tenha uma data, requer, portanto, de uma construção de uma permanência e uma identidade para os conhecimentos. Nesse lugar se posiciona o político que, segundo Guimarães, insere-se na língua por meio da enunciação. Guimarães (2005) afirma que 
o sujeito, ao falar, posiciona-se em um contexto sócio-histórico, pois se inscreve em uma divisão social.

Assim, este trabalho procura entender como se mobiliza a designação "desenvolvimento de língua" e/ou "desenvolvimento linguístico". Entende-se desenvolvimento, de acordo com Nisbet (1980), como consequência de uma decadência na crença no progresso da humanidade. Ao separar-se desse pensamento, segundo Amartya Sem (1999,) o desenvolvimento se define, como um processo de expansão das capacidades que disfrutam os indivíduos e lhes permitem conseguir distintos estilos de vida valorizados como favoráveis por si mesmos, como formas de bem-estar.

Neste estudo, tomamos como referencial teórico, além da Semântica do Acontecimento, a proposta de História das Ideias Linguísticas. A análise enunciativa se centra no texto da Declaração Universal dos Direitos Linguísticos (1996), assumido como acontecimento enunciativo que, por se dar nos espaços de enunciação, é por essência um acontecimento político (Guimarães, 2005), um lugar onde se produz a relação entre línguas, falantes e disputas de poder.

\section{Declaração Universal dos Direitos Linguísticos como acontecimento enunciativo}

A Declaração Universal dos Direitos Linguísticos é um documento publicado pela Unesco como resultado da Conferência Mundial dos Direitos Linguísticos, publicada em 1996, em Barcelona. Segundo subscreve o próprio documento (Unesco, 1996), é consequência de um acordo e se trata de um documento-base, produto de um processo complexo de retrospeção, que põe no debate as diversidades de línguas, sua promoção nos distintos Estados, seu reconhecimento jurídico e sua relação com 0 desenvolvimento, em quadro de "respeito, convivência e benefício recíprocos" (Unesco, 1996).

Para compreender o sentido e a importância, este documento-base reuniu 61 organizações internacionais, 30 centros especializados da Associação Mundial de Escritores (PEN internacional), 40 pesquisadores em direito linguístico e a representação da Unesco, encarregada do patrocínio. Este documento destaca-se por sua institucionalização, associada, por um lado, aos organismos internacionais e aos documentos que permitiram seu surgimento e, por outro lado, às redes especializadas e às propostas teóricas nas quais tem base. Nesse sentido, devido a sua origem institucional e científica, esta declaração, enquanto discurso, pode constituir-se em uma memória da diversidade linguística legitimada $e$, constantemente, atualizada pela aparição de novos estudos e reflexões em distintos contextos socioculturais.

No que se refere aos antecedentes de caráter institucional deste documentobase, pode-se citar como ponto de partida à Declaração Universal dos Direitos Humanos, assinada em 1948. No artigo $2^{\circ}$, expressa-se o direito de toda pessoa a não ser discriminada por nenhuma condição, entre elas a de "raça, cor, sexo, idioma, religião, opinião politica ou qualquer outra índole” (ONU, 1998). Em consequência, nesta carta se reconhece, embora não explicitamente, a diversidade linguística, como um princípio que será desenvolvido tanto no âmbito jurídico como nos estudos da língua. 
Nesse marco histórico e legal, desde 1945, a Unesco já reconhecia em sua Constituição o objetivo de ter a colaboração internacional mediante a cultura, a fim de assegurar "o respeito universal às liberdades fundamentais sem distinção de raça, sexo, idioma ou religião" (Unesco, 1945). Contudo, um pronunciamento específico das Nações Unidas sobre a diversidade linguística aparece meio século depois, como resultado da contribuição que a disciplinarização dos estudos sobre língua e diversidade. Em 1992, na Assembleia Geral da ONU, assina-se a Declaração sobre os direitos das pessoas pertencentes a minorias nacionais ou étnicas, religiosas e linguísticas.

No documento mencionado, reafirma-se o compromisso implicado no princípio básico de não discriminação citado na Carta das Nações Unidas. A Declaração de 1992 considera, nesse sentido, que a promoção e proteção dos direitos das pessoas pertencentes às minorias linguísticas contribuem para estabilidade política e social dos Estados em que vivem. Por esta razão, tal como estabelece a Declaração, ressalta-se o papel das minorias linguísticas como parte do desenvolvimento da sociedade em seu conjunto. Finalmente, em consequência, no seu artigo $4^{\circ}$ destaca a necessidade de envolver estas comunidades no processo de desenvolvimento econômico, afirmando que "os Estados deverão considerar a possibilidade de adoptar medidas adequadas a fim de permitir a participação plena das pessoas pertencentes a minorias no progresso e desenvolvimento económico do seu país" (ONU, 1992).

Além disso, no marco institucional, de jurisdição internacional em que se enquadra a Declaração de 1996, é necessário precisar os documentos resultantes do debate acadêmico especializado sobre língua e diversidade cultural que precedem a Conferência de Barcelona. Um dos mais significativos foi a Declaração de Recife, de 9 de outubro de 1987, como efeito do XXII Seminário da Associação Internacional para o Desenvolvimento da Comunicação Intercultural. Nela, de acordo com a Declaração de 1996, "se recomenda às Nações Unidas que tomem as medidas necessárias com o objetivo de adotar e aplicar uma Declaração Universal de Direitos Linguísticos" (Unesco, 1996).

Outro documento-base que constitui um antecedente relevante da Declaração de 1996 é a Declaração do Comitê de Traduções e Direitos Linguísticos do PEN Club Internacional, assinada em Santiago de Compostela, Espanha, em 1993. Neste documento se debate sobre a proposta de realizar uma conferência mundial de Direitos Linguísticos (Unesco,1996) e se declara que todos os povos têm direito a expressar e desenvolver sua cultura, sua língua e suas normas de organização e, para fazê-lo, deve-se adotar as próprias estruturas políticas educativas, de comunicação e de administração pública, em marcos políticos diferentes.

Como se pode ver, a Declaração Universal dos Direitos Linguísticos é um documento-base que resulta de antecedentes tanto jurídicos como científicos. Por um lado, é herdeiro de uma proposta institucional oficial que se funda nos princípios históricos propostos desde a Carta das Nações Unidas em 1945. Da mesma maneira, estabelece-se como produto de um debate acadêmico orientado ao reconhecimento e à promoção da diversidade linguística como parte do patrimônio cultural necessário para o desenvolvimento no texto da Declaração, a fim de determinar como se relaciona com a língua e como a história entra nela para constituir um processo de institucionalização da memória. 


\section{Referencial teórico}

Como se mencionou acima, o presente artigo se inscreve dentro da linha de pesquisa como História das ideias linguísticas (HIL). Esta linha, de acordo com Nunes (2008a), se iniciou no debate acadêmico como resultado de uma colaboração entre a Universidade Estadual de Campinas e a Universidade Paris 7, na França. Uma característica deste enfoque em seus inícios residia na análise do uso da língua a partir de materiais como relatos de viajantes e missioneiros, testemunhas, manuais, gramáticas e outros documentos produzidos em épocas anteriores. Porém, segundo Nunes (2008a), o diferencial desta disciplina consiste, mais que na fonte utilizada, em assumir uma visão histórica da ciência e, fundamentalmente, de uma nova denominada Ciências da Linguagem. De acordo com Auroux (1992), esta concepção se distingue por entender os estudos de e sobre a linguagem num sentido amplo, considerando a diversidade de suas manifestações no espaço e no tempo. Assim, Auroux situa ciências da linguagem como todo saber constituído mediante o estudo das línguas em suas mais abrangentes diversidades.

É preciso situar nosso objeto em relação só a um campo de fenômenos, apreensíveis á altura da consciência quotidiana. Seja a linguagem humana, tal como ela se realizou na diversidade das línguas; saberes se constituíram a seu respeito; este é nosso objeto. Na medida do possível, exceto no que concerne ao século XIX, é preciso evitar o substantivo "linguístico" conquanto possamos usar o adjetivo, tomado em seu sentido geral de que concerne á linguagem. (AUROUX, 1992, p.14)

Nesse sentido, Auroux (1992) afirma que as Ciências da Linguagem admitem a todo saber produzido sobre a linguagem na história, a toda produção de conhecimento linguístico. Considera, portanto, aos estudos especulativos e aos de natureza prática. Dentre estes últimos, abrange a análise da enunciação, da diversidade de línguas, a escritura, o ensino de línguas, a normativa, etc. Em consequência, tal como afirma Nunes (2008a), dentro da linha da história das ideias linguísticas, é suscetível de estudo todo conjunto de trabalhos que muitas vezes foram considerados só especulativos e, portanto, excluídos pela linguística moderna, baixo o argumento da cientificidade.

A amplitude desta perspectiva permite reconhecer como objetos de estudo, segundo Nunes (2008a), as diversas formas de discurso sobre as línguas. Para abordálos no marco da HIL, a análise deve ter em conta os discursos em suas condições de produção, no contexto onde foram produzidos. Isto evitará considerar estes simplesmente como iniciadores ou antecedentes da ciência moderna.

Dentro da HIL, em consequência, a Ciência da Linguagem os assume como modos específicos de produzir conhecimento sobre a língua em determinadas situações históricas. Nesta lógica, com a finalidade de delimitar o âmbito de estudo devido à amplitude já referida, introduz-se o conceito de documento de arquivo. Orlandi (2002) elabora uma definição do arquivo como discurso documental, como memória institucionalizada. Em um arquivo, de acordo com a autora, são produzidas relações complexas entre saber e a memória que se constituem ao longo da história da linguagem. Desconstruí-las em seus contextos e em seus vínculos institucionais é, pois o exercício da análise de um documento dentro da linha na qual nos situamos. 
De acordo com Nunes (2008b), este trabalho nos conduz a explicar os gestos de interpretação que se encontram implicados na elaboração de um documento de arquivo, no processo de sua construção. Este trabalho de interpretação direciona os sentidos, o que vai produzir uma memória estabilizada. Segundo Orlandi (2002), se bem é certo que todo dizer constitui já um gesto de interpretação, uma posição na memória, no caso de um arquivo, a memória se encontra estabilizada, institucionalizada. "Já o que estamos chamando arquivo é a memória institucionalizada, estabilização de sentidos. No arquivo, o dizer é documento, atestação de sentidos, efeito de relações de forças" (ORLANDI, 2002, p.15).

O conceito de arquivo proposto por Orlandi pode se complementar pelo afirmado por Foucault (2002). De acordo com ele, um arquivo não é somente um conglomerado de documentos preservados no tempo. Ao contrário, afirma que um arquivo define 0 modo como devem ser lidos na atualidade e sua relação com o passado, com a memória do já dito e com o que ainda está por dizer-se. Segundo o autor, o arquivo funciona como meio de seleção daqueles enunciados que se materializam como acontecimentos.

Nesse sentido, uma caraterística dos enunciados do arquivo é que "dão vida constante aos acontecimentos" (Foucault, 2002, p.149). De acordo com ele, existe uma memória nos enunciados do arquivo que funciona em relação com o presente da leitura. É, por isso, que um arquivo não pode ser lido de uma maneira única, deve ser lido tendo em conta a incompletude em que se constitui. Ao respeito, Foucault postula que, em um arquivo, os enunciados adquirem seu significado da relação que têm com outros enunciados, dentro de distintas temporalidades, considerando instituições de várias épocas e sua própria historicidade. A esse conjunto, o autor o denomina sistema de enunciabilidade (p.150).

A partir desta definição de arquivo, pode-se afirmar que o discurso documental se entende, segundo Nunes (2008b), como um saber científico, que se constitui como tal relação com as instituições que o produzem, os sujeitos de ciência que o respaldam e os meios pelos que circula este saber dentro de um contexto histórico determinado. Em tal sentido, de acordo com o autor, o estudo deste discurso compreende a análise dos instrumentos (manuais, gramáticas, normas, dicionários), das instituições que os elaboram e as condições em que se produzem estes instrumentos na prática científica. Uma obra se converte, dentro desta perspectiva, em um texto documental ou documento de arquivo quando é historicizada, quando se converte em parte de um saber documental de caráter, geralmente, metalinguístico.

Nesta lógica, para relacionar o saber linguístico com determinadas temporalidades, nas palavras de Nunes, é importante o conceito de horizonte de retrospeção. Para definir este, o autor cita a Auroux (2006 apud NUNES 2008a):

Nomeamos horizonte de retrospecção o conjunto desses conhecimentos antecedentes (Auroux, 1987). Um horizonte de retrospecção pode ser estruturado de diferentes formas. Os conhecimentos podem figurar de modo indistinto como conhecimentos comuns. Mas eles podem também ser indexados, com autores, até mesmo com datas. A existência dos horizontes de retrospecção é um testemunho de que o conhecimento tem necessariamente relação com o tempo; não há conhecimento instantâneo, o que não significa que o objeto do conhecimento ou seu 
valor sejam temporais, como sustenta o relativismo. (AUROUX, 2006, p.107-108, NUNES, 2008a, p.85)

Conforme Auroux (2006 apud Nunes 2008a), o estudo da estrutura dos horizontes de retrospecção e o modo como o domínio dos objetos é mediado pela temporalidade são fundamentais para abordar o tema da história das ciências. Como consequência disso, a história da ciência deixa de considerar-se dentro de uma temporalidade idealista, que transcende ao espaço. Segundo a proposta de Auroux, citada por Nunes (2008a), esta se remete aos espaços. Por exemplo, em distintas tradições linguísticas, o estudo deste horizonte de retrospecção permite evidenciar formas específicas de temporalidade, o que inclui maneiras próprias do passado distinguíveis das que formam parte da ciência contemporânea e outra que se retomam delas.

Esta inserção do histórico no discurso científico faz possível a proposta de Auroux (1992) de que todo conhecimento é uma realidade histórica. Este fato pressupõe não só a abordagem desde um horizonte de retrospecção, mas também a existência do que ele denomina horizonte de projeção. Desta maneira, a temporalidade pode ser compreendida pelos discursos já ditos que se inscrevem no discurso como parte da memória que esta na constituição discursiva. Assim, o autor afirma que:

Todo conhecimento é uma realidade histórica, sendo que seu modo de existência real não é atemporalidade ideal de ordem lógica do desfraldamento do verdadeiro, mas a temporalidade ramificada da constituição cotidiana do saber. Porque é limitado, o ato de saber possui, por definição, uma espessura temporal, um horizonte de retrospecção, assim como um horizonte de projeção. (AUROUX, 1992, p.11)

Guimarães (2005) propõe uma teoria na que inclui uma relação de historicidade no conceito de enunciação, atribuindo-Ihe um caráter social. Isto é que o acontecimento se refere ao contexto sócio-histórico-ideológico. Desta maneira, o enunciado é considerado como uma unidade discursiva (Guimarães, 2005). Em este sentido, toda prática social reúne entre seus rasgos internos ao enunciado. Este, a sua vez, implica em sua definição à relação entre palavra e sujeito, mais especificamente, com posições do sujeito. A partir disso, o sentido de todo enunciado considerará como um complexo conjunto de formações imaginárias do sujeito, de seu interlocutor e do assunto desenvolvido na interação.

De acordo com Guimarães (2005), o sentido do enunciado se dá através da relação de outros enunciados e é impossível pensar fora de esta relação à linguagem e o sentido. Em outras palavras, o sentido transforma ao enunciado em seu lugar de observação. Portanto, para identificar o significado de uma forma ou expressão é indispensável conhecer a constituição do sentido do enunciado. Nesse contexto, é impossível considerar o sentido de uma forma sem ter em conta seu funcionamento ao interior de um texto.

O sentido de um elemento linguístico tem a ver com o modo como este elemento faz parte de uma unidade maior ou mais ampla. Vê-se que ao fazer este uso da relação integrativa, a despeito de Benveniste ter dito que ela não permitia passar do limite do enunciado, estou dizendo que há uma passagem do enunciado para o texto, para o acontecimento, que 
não é segmental. E esta é a relação de sentido. (GUIMARÃES, 2005: p. 7)

E é nesta relação de enunciados que a língua adota historicidade. Além disso, tratar da enunciação é tratar do sujeito que enuncia. E se considera que a relação do sujeito com a linguagem ocorre no acontecimento denominado enunciação, resulta evidente que esta deve ser entendida como um espaço em que o sentido se constrói como resultado de uma elaboração histórica.

O político na linguagem também é considerado por Guimarães (2005), além do tratamento do sentido pensado, sem dúvida, desde uma perspectiva histórica. Segundo o autor, no centro do dizer se instala certo grau de conflito motivado pelo político. Este aspecto está constituído por uma forma de contradição entre as normas desiguais das instituições sociais e a necessidade de pertença dos não incluídos. Neste caso, o espaço de enunciação se reduz ao espaço político. A enunciação, portanto, enquanto acontecimento da linguagem, é resultado do funcionamento da língua, constituída em sua temporalidade e materialidade histórica.

Uma das características mais importantes do conceito de acontecimento, de acordo com Guimarães (2005), é a constituição de uma temporalidade, portanto é preciso que as palavras contenham uma memória histórica de suas enunciações. 0 acontecimento, assim, é sempre una nova temporalização, um novo espaço de convivência, sem aquela não há sentido, não há acontecimento de linguagem e, evidentemente, não há enunciação.

\begin{abstract}
A temporalidade do acontecimento constitui o seu presente e um depois que abre o lugar dos sentidos, e um passado que não é lembrança ou recordação de pessoas e de fatos anteriores. o passado é, no acontecimento, rememoração de enunciações, ou seja, se dá como parte de uma nova temporalização, tal como a latência de futuro. (GUIMARÃES, 2005; 12)
\end{abstract}

Desta maneira, em uma análise dos sentidos de uma palavra, a alternativa mais viável é uma análise enunciativa que define a enunciação como acontecimento.

\title{
4. 0 desenvolvimento e o desenvolvimento da língua na Declaração Universal
}

Para que seja possível compreender como se mobilizam, se articulam e se reescrevem os sentidos da palavra desenvolvimento relacionado com a língua ou as línguas no texto da Declaração, realizaram-se recortes daqueles fragmentos em que esta palavra aparece. Assim poderemos identificar e observar, à maneira de ilustração, como se forma um conhecimento produzido sobre esta noção, associado a uma temporalidade determinada.

Recorte 1

"Considerando que a maioria das línguas ameaçadas do mundo pertence a comunidades não soberanas e que dois dos principais fatores que impedem o desenvolvimento destas línguas e aceleram o processo de substituição linguística são a ausência de autogoverno e a política de Estados que impõem a sua estrutura político-administrativa e a sua língua". 
Neste primeiro recorte, pode-se observar como a palavra desenvolvimento reescreve "reivindicação" em tanto posto a "ameaça", "imposição". Nesse sentido, o desenvolvimento se transforma no objetivo construído sobre a base do "autogoverno" e a "rejeição ao imposto". Portanto, a palavra analisada mobiliza conceitos como "liberdade", "soberania", "autonomia", entendidos em relação com uma articulação de noções como "respeito às minorias, às comunidades ameaçadas". Esta vinculação reescreve o afirmado pela Declaração da Assembleia das Nações Unidas de 1992, em tanto "promoção de desenvolvimento das minorias". Assim, a substituição linguística, considerada como imposição, articula-se como a reformulação oposta ao termo desenvolvimento.

Recorte 2

"Se torna, portanto, necessário que os direitos linguísticos sejam considerados
sob uma perspectiva global, para que se possam aplicar em cada caso as
soluções específicas adequadas; Conscientes de que é necessária uma
Declaração Universal dos Direitos Linguísticos que permita corrigir os
desequilíbrios linguísticos com vista a assegurar o respeito e o pleno
desenvolvimento de todas as línguas e estabelecer os princípios de uma paz
linguística planetária justa e equitativa, como fator-chave da convivência
social".

O segundo recorte permite observar como a palavra desenvolvimento movimenta dois conceitos fundamentais: "justiça" e "equidade". O desenvolvimento, ao interior do recorte, toma um caráter universal, pois se deve manifestar "em todas as línguas". Nesse sentido, esta palavra mobiliza também o conceito de "inclusão" como meio para alcançar a meta da equidade. Além disso, permite demonstrar a constituição da Declaração como discurso documental, mas também como discurso político, pois a norma, neste caso, mostra como "necessária" a reafirmação dos direitos linguísticos. Nessa lógica, pode-se ver a mobilização de conceitos como "correção", "solução". Em síntese, o desenvolvimento atualiza que os sentidos de "respeito", "convivência", "paz" são legitimados pelo jurídico, pela submissão à norma estabelecida.

Recorte 3

"Mais concretamente, a situação atual caracteriza-se por:- numa perspectiva cultural, tornar o espaço de comunicação mundial plenamente compatível com a participação equitativa de todos os povos, de todas as comunidades linguísticas e de todas as pessoas no processo de desenvolvimento"

Neste parágrafo, mostra-se como desenvolvimento, dentendido esta vez como processo, mobiliza o conceito de "progresso", dentro da definição de Nisbet (1980). Esta associação se comprova pela articulação de expressões como "todas as pessoas", "todos os povos", "todas as comunidades linguísticas" que, na dimensão do desejável, 
se deslocam para o desenvolvimento. Esta palavra, então, já não se designa como meio; ao contrário: se reescreve como "processo" e como "final". Portanto, no fragmento, os conceitos de "universal", "integração", "caminho" e novamente "equidade" são mobilizados na escrituração da palavra desenvolvimento.

Recorte 4

R4: "Numa perspectiva econômica, promover um desenvolvimento duradouro baseado na participação de todos e no respeito pelo equilíbrio ecológico das sociedades e por relações equitativas entre todas as línguas e culturas. Por todas estas razões, esta Declaração toma como ponto de partida as comunidades linguísticas e não os Estados, e inscreve-se no quadro do reforço das instituições internacionais capazes de garantir um desenvolvimento duradouro e equitativo para toda a humanidade, e tem como finalidade favorecer um quadro de organização política da diversidade linguística baseado no respeito, na convivência e no benefício recíproco".

Este recorte permite associar o desenvolvimento não como um objetivo ideal. Ao contrário, quando se considera desde "uma perspectiva econômica", mobiliza conceitos como "inclusão", "integração", "equidade" entre indivíduos e comunidades, mas também entre línguas. A novidade que pode observar-se neste fragmento é que este estado de desenvolvimento se deve "garantir por meio da cooperação internacional". Por tanto, a palavra em questão mobiliza noções como "direito fundamental", "reconhecimento jurídico". Visto assim, o desenvolvimento pode alcançar a caraterística de "duradouro", "favorável" e "recíproco". Definitivamente, esta noção de desenvolvimento reafirma a condição de texto documental da Declaração, como discurso onde se insere uma memória histórica associada ao "sujeito de direito" e um meio para a circulação da "inclusão" como norma jurídica.

\section{Considerações finais}

Sobre a base do refletido, pode-se reconhecer a importância da proposta teórica da História das ideias Linguísticas. A partir dela, é possível ampliar o horizonte das discussões linguísticas, enquadradas no modelo da ciência moderna, para uma concepção que considere os estudos de e sobre a língua (Auroux, 1992). Isto permite considerar a diversidade de suas manifestações no espaço e no tempo, é dizer, na totalidade das Ciências da Linguagem (Auroux, 1992).

Assim, podem-se abranger distintos objetos de estudo, entre eles, um documento jurídico como a Declaração Universal dos Direitos Linguísticos (1996). A DUDL pode ser considerada, além disso, como um acontecimento enunciativo, como um acontecimento político. Guimarães (2005) afirma que o sujeito, ao falar, se posiciona em um espaço de divisão social. Nesse contexto, o sentido da designação desenvolvimento, obtido das relações com o resto de enunciados se associa com 0 processo no qual todas as comunidades linguísticas e, por extensão, todas as línguas sobre a base da geração de um "espaço de comunicação mundial plenamente compatível com a participação equitativa de todos os povos". O desenvolvimento representaria a resolução do conflito motivado pelo político (Guimarães, 2005). 
A partir do exposto, pode-se afirmar que os recortes selecionados são úteis para ilustrar a maneira como o político se insere no dizer e, portanto, se associa ao proposto por Orlandi (2002) sobre as políticas de língua. Este fato se poder ver em R2, quando se afirma que "é necessária uma Declaração Universal dos Direitos Linguísticos que permita corrigir os desequilíbrios linguísticos" (DUDL). Esta asseveração pressupõe que a Declaração se insere em um espaço de relações de poder e de disputa. O documento em consequência se constitui pela força da enunciação mesma em um mediador que pretende resolver essa situação de conflito. Esta relação é só um exemplo que ratifica, portanto, a relevância da Declaração no debate das políticas linguísticas.

\section{Referências}

AUROUX, S. A revolução tecnológica da gramatização. Tradução de Eni Puccinelli Orlandi. Campinas: Ed. da UNICAMP, 1992.

FOUCAULT, M. La arqueología del saber. Buenos Aires: Siglo XXI Editores, 2002.

GUIMARÃES, E. Semântica do Acontecimento. Campinas: Pontes, 2005.

MARIANI, B. S. C. A língua como questão nos primórdios da história da colonização africana: a Crônica da Guiné, de G. E. de Zurara. Gragoatá - Revista do Instituto de Letras da UFF, NITERÓI, v. 19, p. 177-192, 2005.

NUNES, J. H. O discurso documental na história das idéias lingüísticas e o caso dos dicionários. São Paulo: Revista Alfa, 52 (1): 81-100, $2008 \mathrm{a}$.

NUNES, J. H. Uma articulação da análise de discurso com a história das ideias linguísticas. Santa Maria: Letras, v. 18, n. 2, p. 107-124, jul./dez. 2008b

NISBET, R. Historia de la idea del progreso. Gedisa: Barcelona, 1980.

ORLANDI, E. Língua e conhecimento linguístico. São Paulo: Cortez, 2002.

ONU. Declaração Universal dos Direitos Humanos. Representação da Unesco no Brasil. $1998 . \quad$ Disponível em: $<$ http://unesdoc.unesco.org/images/0013/001394/139423por.pdf Acesso 08/07/15>. Acesso 08/07/15

ONU. Declaração sobre os Direitos das Pessoas Pertencentes a Minorias Nacionais ou Étnicas, Religiosas e Linguísticas. Gabinete de Documentação e Direito Comparado, 1992. <http://direitoshumanos.gddc.pt/3 2/lIIPAG3 2 10.htm >. Acesso 08/07/15

SEN, Amartya. Romper el ciclo de la pobreza: Invertir en la infancia. Conferencia Magistral, BID. 1999. Disponível em: <www.iadb.org/sds/doc/SOC\%2D114S.pdf>. Acesso em: 06/07/15. 
UNESCO. Constituição da Organização das Nações Unidas para a Educação, a Ciência e a Cultura. Representação da Unesco no Brasil. 1945. Disponível em: $<$ http://unesdoc.unesco.org/images/0014/001472/147273por.pdf $>$. Acesso em: $13 / 03 / 15$

UNESCO. Declaração Universal dos Direitos Linguísticos. 1996. Disponível em: http://www.dhnet.org.br/direitos/deconu/a pdf/dec universal direitos linguisticos.pdfAc esso em: 08/07/15. 